\title{
Evaluation of Unsaturated-Zone Solute-Transport Models for Studies of Agricultural Chemicals
}

Open-File Report 2005-1196 


\section{Evaluation of Unsaturated-Zone Solute-Transport Models for Studies of Agricultural Chemicals}

By Bernard T. Nolan, E. Randall Bayless, Christopher T. Green, Sheena Garg, Frank D. Voss, David C. Lampe, Jack E. Barbash, Paul D. Capel, and Barbara A. Bekins

Open-File Report 2005-1196 


\title{
U.S. Department of the Interior \\ Gale A. Norton, Secretary \\ U.S. Geological Survey \\ Charles G. Groat, Director
}

\author{
U.S. Geological Survey, Reston, Virginia: 2005 \\ For sale by U.S. Geological Survey, Information Services \\ Box 25286, Denver Federal Center \\ Denver, CO 80225 \\ For more information about the USGS and its products: \\ Telephone: 1-888-ASK-USGS \\ World Wide Web: http://www.usgs.gov/ \\ Any use of trade, product, or firm names in this publication is for descriptive purposes only and does not imply \\ endorsement by the U.S. Government. \\ Although this report is in the public domain, permission must be secured from the individual copyright owners to \\ reproduce any copyrighted materials contained within this report.
}




\section{Conversion Factors SI to Inch/Pound}

\begin{tabular}{|c|c|c|}
\hline Multiply & By & To obtain \\
\hline \multicolumn{3}{|c|}{ Length } \\
\hline centimeter $(\mathrm{cm})$ & 0.3937 & inch (in.) \\
\hline millimeter (mm) & 0.03937 & inch (in.) \\
\hline meter $(\mathrm{m})$ & 3.281 & foot $(\mathrm{ft})$ \\
\hline \multicolumn{3}{|c|}{ Area } \\
\hline square centimeter $\left(\mathrm{cm}^{2}\right)$ & 0.001076 & square foot $\left(\mathrm{ft}^{2}\right)$ \\
\hline \multicolumn{3}{|c|}{ Volume } \\
\hline milliliter (mL) & 0.0338 & ounce \\
\hline liter $(\mathrm{L})$ & 0.2642 & gallon (gal) \\
\hline cubic centimeter $\left(\mathrm{cm}^{3}\right)$ & 0.06102 & cubic inch $\left(\mathrm{in}^{3}\right)$ \\
\hline \multicolumn{3}{|c|}{ Mass } \\
\hline $\operatorname{gram}(\mathrm{g})$ & 0.0022 & pound (lb) \\
\hline \multicolumn{3}{|c|}{ Density } \\
\hline gram per cubic centimeter $\left(\mathrm{g} / \mathrm{cm}^{3}\right)$ & 62.4220 & pound per cubic foot $\left(\mathrm{lb} / \mathrm{ft}^{3}\right)$ \\
\hline \multicolumn{3}{|c|}{ Hydraulic conductivity } \\
\hline centimeter per day $(\mathrm{m} / \mathrm{d})$ & 0.3937 & inch per day (in./d) \\
\hline \multicolumn{3}{|c|}{ Concentration } \\
\hline milligram per liter (mg/L) & 0.000062426 & pound per cubic foot $\left(\mathrm{lb} / \mathrm{ft}^{3}\right)$ \\
\hline microgram per liter $(\mu \mathrm{g} / \mathrm{L})$ & 0.0062426 & pound per cubic foot $\left(\mathrm{lb} / \mathrm{ft}^{3}\right)$ \\
\hline milligram per kilogram $(\mathrm{mg} / \mathrm{kg})$ & 0.002 & pound per ton $(\mathrm{lb} /$ ton $)$ \\
\hline
\end{tabular}

Temperature in degrees Celsius $\left({ }^{\circ} \mathrm{C}\right)$ may be converted to degrees Fahrenheit $\left({ }^{\circ} \mathrm{F}\right)$ as follows:

$$
{ }^{\circ} \mathrm{F}=\left(1.8 \times{ }^{\circ} \mathrm{C}\right)+32
$$

\section{Acronyms}

1-D - one dimensional

2-D - two dimensional

3-D - three dimensional

ACT - Agricultural Chemical Team

ATR - Atrazine

$\mathrm{Br}-$ Bromide

CA - California

CALF - CALculates Flow, leaching of pesticides in field soils

CREAMS - Chemicals, Runoff, Erosion and Agricultural Management Systems

DDA - Didealkyatrazine

DEA - Desethylatrazine

ET - Evapotranspiration

GLEAMS - Groundwater Loading Effects of Agricultural Management Systems

GUI - graphical user interface

HYA - Hydroxyatrazine

IN - Indiana
Ksat - Saturated hydraulic conductivity

LEACHM - Leaching Estimation and Chemistry Model

LEACHP - Leaching Estimation and Chemistry Model for Pesticides

NOAA - National Oceanic and Atmospheric Administration

NAWQA - National Water-Quality Assessment Program

PRZM - Pesticide Root Zone Model

RZWQM - Root Zone Water Quality Model

SWAT - Soil and Water Assessment Tool

USDA - United States Department of Agriculture

USDA-ARS - United States Department of Agriculture - Agricultural Research Service USGS - United States Geological Survey UZ - unsaturated zone VS2DT - Variably Saturated Two Dimensional Transport 


\section{Contents}

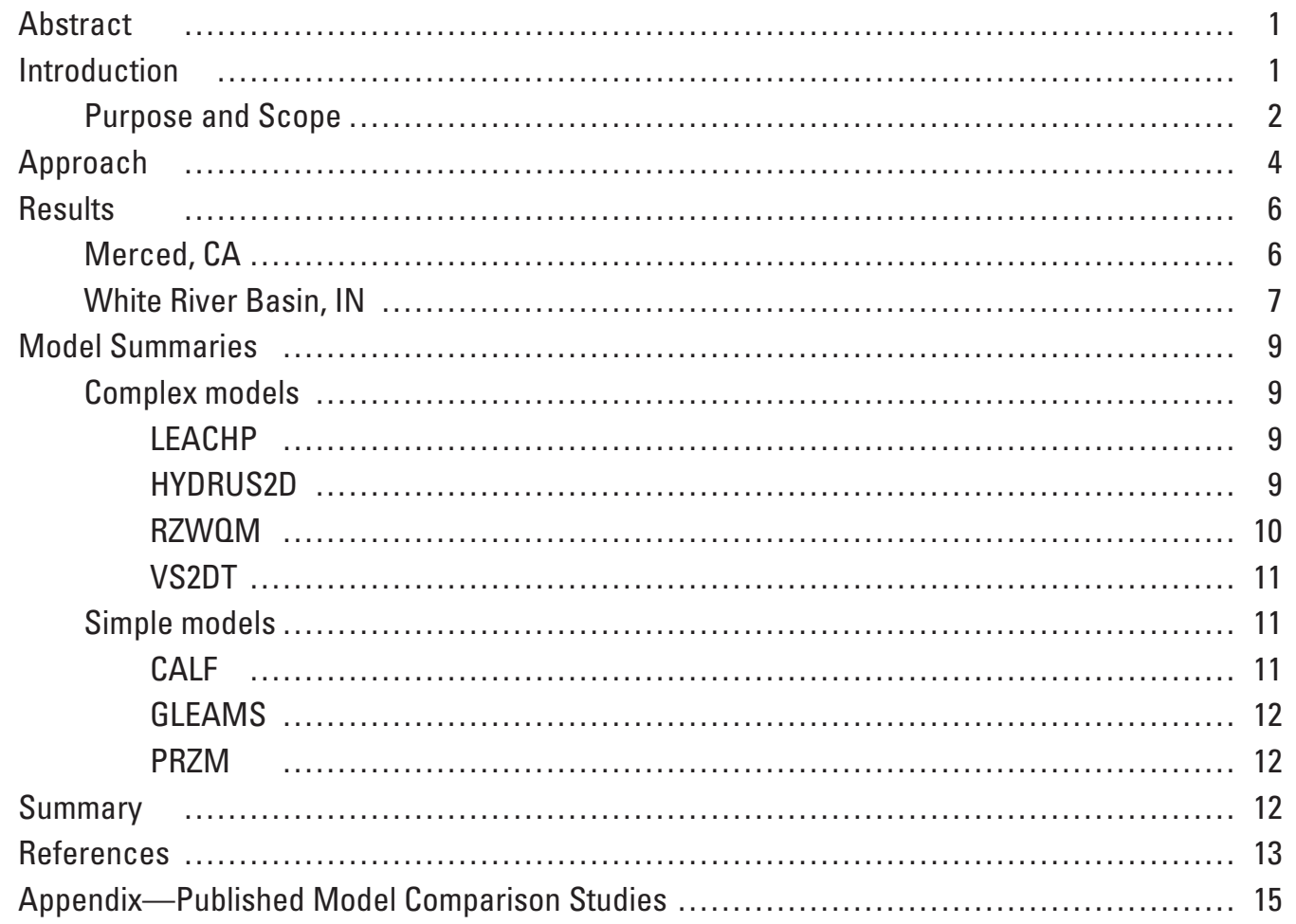

\section{Figures}

1-8. Graphs showing:

1a. Fit of van Genuchten moisture-retention function to field data at Merced, California, for sediment type $1(0-125 \mathrm{~cm}$ and $175-300 \mathrm{~cm}$ depths)

1b. Fit of Brooks-Corey moisture-retention function to van Genuchten values derived from grain size data at the White River Basin (1.45 meters) $\ldots \ldots \ldots \ldots \ldots \ldots \ldots \ldots$

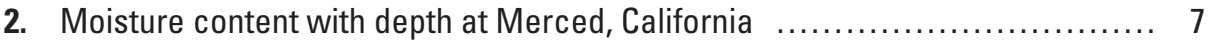

3. Matric potential with depth at Merced, California ......................... 7

4. Bromide concentration with depth at Merced, California ..................... 7

5. Matric potential with time at White River Basin, Indiana $\ldots \ldots \ldots \ldots \ldots \ldots \ldots \ldots$

6. Atrazine concentration with time at White River Basin, Indiana $\ldots \ldots \ldots \ldots \ldots . \ldots$

7. Desethylatrazine concentration with time at White River Basin, Indiana $\ldots \ldots \ldots \ldots$

8. Didealkylatrazine concentration with time at White River Basin, Indiana $\ldots \ldots \ldots \ldots \quad 9$

\section{Tables}

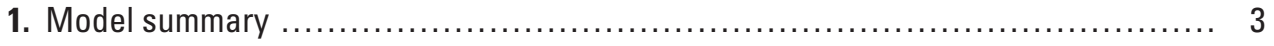

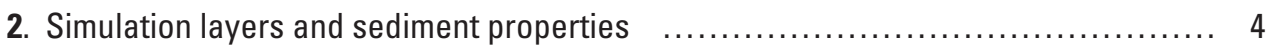

3. Model parameters associated with chemical transport of bromide, atrazine, and atrazine degradates 


\title{
Evaluation of Unsaturated-Zone Solute-Transport Models for Studies of Agricultural Chemicals
}

\author{
By Bernard T. Nolan, E. Randall Bayless, Christopher T. Green, Sheena Garg, Frank D. Voss, David C. Lampe, \\ Jack E. Barbash, Paul D. Capel, and Barbara A. Bekins
}

Abstract

Seven unsaturated-zone solute-transport models were tested with two data sets to select models for use by the Agricultural Chemical Team of the U.S. Geological Survey's National Water-Quality Assessment Program. The data sets were from a bromide tracer test near Merced, California, and an atrazine study in the White River Basin, Indiana. In this study the models are designated either as complex or simple based on the water flux algorithm. The complex models, HYDRUS2D, LEACHP, RZWQM, and VS2DT, use Richards' equation to simulate water flux and are well suited to process understanding. The simple models, CALF, GLEAMS, and PRZM, use a tipping-bucket algorithm and are more amenable to extrapolation because they require fewer input parameters. The purpose of this report is not to endorse a particular model, but to describe useful features, potential capabilities, and possible limitations that emerged from working with the model input data sets. More rigorous assessment of model applicability involves proper calibration, which was beyond the scope of this study.

Uncalibrated ("cold") simulations were run using all seven models to predict the transport of bromide (Merced) and the transport and fate of atrazine and three of its transformation products (White River Basin). Among the complex models, HYDRUS2D successfully predicted both the surface retention and accumulation of bromide at depth at the Merced site, whereas RZWQM and VS2DT predicted only the latter. RZWQM predictions of atrazine were closest to observed values at the White River Basin site, where preferential flow has been observed. LEACHP predicted smaller solute concentrations than observed at both the Merced and White River Basin sites. Among the simple models, CALF predicted the highest values of atrazine and deethylatrazine at the measurement depth of 1.5 meters. CALF includes the Addiscott flow option for preferential flow, and also accepts user-specified dispersivity. PRZM underpredicted solute concentrations, probably because control of dispersion is a problem with this model. GLEAMS has a maximum simulation depth of 1.5 meters, which is limiting for mass-balance purposes because it creates a potential disconnect between unsaturated-zone transport and the water table.
Of the models tested, RZWQM, HYDRUS2D, VS2DT, GLEAMS and PRZM had graphical user interfaces. Extensive documentation was available for RZWQM, HYDRUS2D, and VS2DT. RZWQM can explicitly simulate water and solute flux in macropores, and both HYDRUS2D and VS2DT can simulate water and solute flux in two dimensions. The version of RZWQM tested had a maximum simulation depth of 3 meters. The complex models simulate the formation, transport, and fate of degradates of up to three to five compounds including the parent, with the exception of VS2DT, which simulates the transport and fate of a single compound.

\section{Introduction}

One of the primary goals in the second decade of the U.S. Geological Survey's (USGS) National Water-Quality Assessment Program (NAWQA) is to refine understanding of key processes that control contaminant behavior in the Nation's water resources. In particular, extensive use of fertilizers and pesticides in agricultural areas can affect the quality of surface and ground waters. Improved understanding of relations among contaminant sources, their transport through the hydrologic system, and effects on water quality will provide the basis for predicting water-quality conditions in unmonitored areas. To achieve this goal, the Agricultural Chemical Team (ACT) is conducting studies of small stream basins (tens of square kilometers in size) in five agricultural areas associated with selected 2001 NAWQA study units. The ACT studies focus on the major aspects of the hydrologic cycle, including the unsaturated zone, ground-water flow, and ground-water/ surface-water interactions.

Although numerous unsaturated-zone (UZ) model comparison studies have been conducted by other researchers in specific locales (appendix), the NAWQA ACT studies encompass a diverse range of environmental settings and management practices across both semiarid and humid climates. Because of this diversity, both one-dimensional and two-dimensional flow regimes are expected, and some preferential flow is anticipated. Currently, no single UZ code accommodates all of these conditions. Several models were tested with available data to determine potential applicabil- 
ity to the NAWQA data sets. The four "complex models" that were tested use Richards' equation for water flux. These models will be used to evaluate physical and chemical processes affecting contaminant transport and fate at intensive UZ monitoring sites. Complex models typically require more input data than their simple counterparts. In contrast, the three "simple models" tested use a "tipping-bucket" algorithm for water flux, and therefore, require fewer input data. The tipping bucket algorithm assumes that water in excess of field capacity moves down to the next soil compartment, provided that the next compartment is not saturated. Simple models will be used to extrapolate data from intensive UZ study sites to locations with limited data (e.g., soil texture from soil survey databases). The simple model results will be used to derive mass balances of water and solutes for the entire stream basin in each ACT study area.

\section{Purpose and Scope}

The objective of this study was to evaluate ease of use and differences in model output as related to model capabilities. Differences in model output have potential implications for model applicability, but are difficult to evaluate without calibrating the models. Calibration can reduce model parameter uncertainty and allow for more robust comparison of modeling results. Model calibration was not performed, however, because this was outside of the scope of this study. Even without calibration, differences in model output can yield insight into each model's ability to represent the physical system and processes affecting that system. For example, certain tippingbucket models cannot simulate upward water flux by capillary rise so they tend to overpredict percolation (Garratt and others, 2002). Similarly, models that do not simulate preferential flow might be inappropriate in areas with highly structured, cracked soils (such as the White River Basin, Indiana), and their predictions often differ from dual porosity models such as RZWQM.

The purpose of this report is not to endorse a particular model, but to describe the results of the model evaluations. Features of $20 \mathrm{UZ}$ models were compiled in a spreadsheet for initial comparison. Seven were selected for evaluation using test data sets (table 1), based on the following criteria:

- Quality of documentation

- Ease of use

- Available within the public domain

- Source code available for modification

- History of successful use by regulatory or other agency

- Anticipation of ongoing support

- At least one complex model for process understanding

- One simple model for scale-up and mass-balance estimates
- At least one complex model should have preferential flow capability

- At least one complex model should have two-dimensional (2-D) capability

The complex models chosen for evaluation were HYDRUS2D, LEACHP, RZWQM, and VS2DT; and the simple models were CALF, GLEAMS, and PRZM. Major processes simulated by the models are shown in table 1 .

The test data sets for model evaluation were selected using several criteria established on the basis of anticipated UZ modeling needs in ACT study areas. These criteria were:

- Comprehensive field data set for model input and comparison with model output, including on-site climate data, soil descriptions, and soil-moisture and soluteconcentration measurements through time and/or space.

- Both conservative transport (e.g., bromide) and reactive transport with parent compound (e.g., atrazine) and degradates in measurable concentrations.

- Both relatively homogeneous soils and also structured soils with documented preferential flow.

- Range of climate conditions.

- Located near ACT studies of interest.

The two data sets satisfying these criteria that were used in the model evaluation were:

- Merced, California (CA), bromide tracer concentration profile measured January 25, 1993 (located near the San Joaquin-Tulare River Basins ACT study); and

- White River Basin, Indiana (IN), atrazine study, site C, sample depth 150 centimeters $(\mathrm{cm})$ (data collected May - September 1994) (located near the White, Great, and Little Miami River Basins ACT study).

The Merced, CA, site features a conservative tracer (bromide) and the White River Basin, IN, site features reactive compounds, including measurable concentrations of degradates. The Merced soils are relatively homogeneous whereas the White River Basin site has highly structured soils exhibiting preferential flow (Bayless, 2001). The sites encompass both semiarid (CA) and humid (IN) climate conditions.

Because of time and budget constraints, modeling was limited to one lysimeter location and depth at the White River Basin site, and one concentration profile on a single date in the case of the Merced site. Five modelers simultaneously tested one or more of the seven models so that the evaluations could be conducted in a timely manner. The bulk of the time spent on the project involved becoming familiar with the codes and parameterizing the models for the two sites. Concerted effort was dedicated to acquiring an internally consistent set of pesticide parameters that reflected the literature and emphasized the most recently published information. 


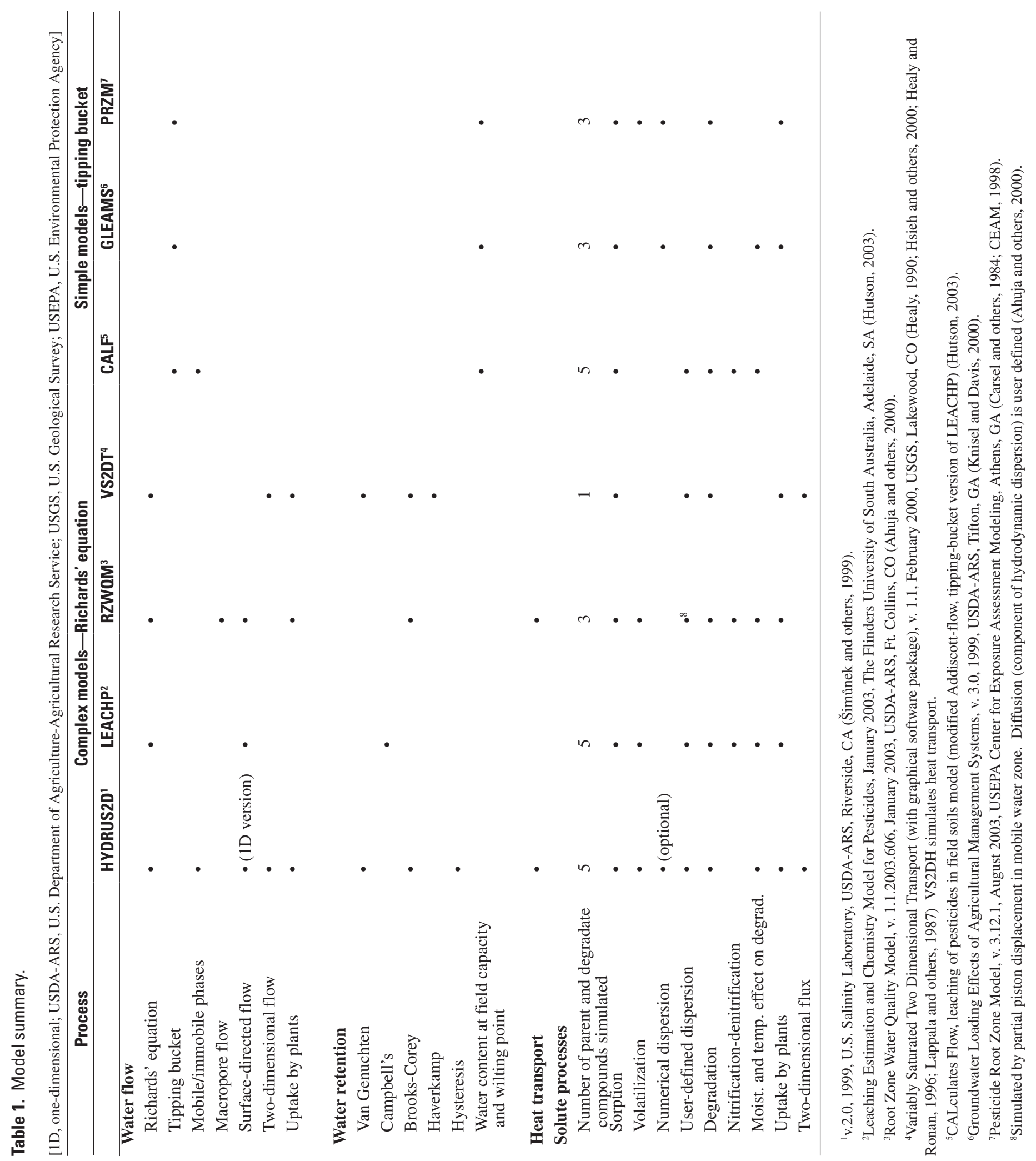




\section{Approach}

Each of the seven unsaturated zone models was tested with the two data sets and evaluated for ease of use and potential to simulate processes of interest. All models were tested via "cold" or forward simulation, without calibration. Proper calibration involves inverse modeling to estimate parameter values that optimally fit the observed data (Hill and others, 2000). Manual calibration was not considered because the process entails numerous disadvantages, such as subjectivity in visual assessment of fit and in deciding when to end the calibration; the difficulty of simultaneously calibrating more than two parameters; and the lack of statistical information on calibrated parameters (Dubus and others, 2002). In contrast, cold simulation involves a single run using the best estimates of model input parameters. Cold simulation tests both the model and the parameterization process, which frequently involves informed judgment and use of algorithms to derive parameters not readily available (e.g., water-retention functions in complex models). Finally, cold simulation is appropriate where potential use without calibration is anticipated, such as by a regulatory agency.

The physical domain was set up using the simulation layers shown in table 2 and corresponding, average values of sediment texture. Depth intervals with similar texture were merged into thick layers at the Merced site. At the White River Basin site, all layers were simulated to test model capabilities in heterogeneous, highly structured soils. Key sediment properties are shown for each UZ sampling interval in table 2. Saturated hydraulic conductivity $\left(\mathrm{K}_{\text {sat }}\right)$ was obtained from field or laboratory measurements at both sites. Climate data are from a combination of onsite data and data from nearby National Oceanic and Atmospheric Administration (NOAA) stations.

Objective comparison of the models required use of the same input values for parameters common to all seven models. Compounds simulated by the models were:

- Merced, CA:

bromide $(\mathrm{Br})$

- White River Basin, IN:

atrazine (ATR) (parent)

desethylatrazine (DEA) (daughter)

hydroxyatrazine (HYA) (daughter)

didealkylatrazine (DDA) (granddaughter)

Values of fate and transport parameters common to the models are shown in table 3 . In the case of atrazine and its degradates, best estimates based on literature sources generally were used; however, transformation rates based on a prior field study (Bayless, 2001) were used in lieu of laboratory values from the literature. The latter were $2-4$ orders of magnitude lower than the field-derived values $\left(0.025-0.035 \mathrm{day}^{-1}\right)$, which would have significantly reduced predicted concentrations of atrazine degradates. Field transformation rates were emphasized because laboratory conditions do not represent transient and spatially variable conditions encountered in the field. Laboratory transformation rates commonly differ

Table 2. Simulation layers and sediment properties.

$\left[\mathrm{K}_{\text {sat }}\right.$, saturated hydraulic conductivity; $\mathrm{cm} / \mathrm{d}$, centimeters per day; $\mathrm{g} / \mathrm{cm}^{3}$, grams per cubic centimeter]

\begin{tabular}{|c|c|c|c|c|c|c|}
\hline $\begin{array}{l}\text { Depth } \\
\text { (cm) }\end{array}$ & $\begin{array}{c}\text { Simulated } \\
\text { layer }\end{array}$ & $\begin{array}{c}K_{\text {sat }} \\
(\mathrm{cm} / \mathrm{d})\end{array}$ & $\begin{array}{l}\text { Bulk den- } \\
\text { sity }\left(\mathbf{g} / \mathrm{cm}^{3}\right)\end{array}$ & Sand & $\begin{array}{c}\text { Percent } \\
\text { Silt }\end{array}$ & Clay \\
\hline \multicolumn{7}{|c|}{ Merced CA } \\
\hline 5 & 1 & 37.4 & 1.25 & 76.29 & 21.35 & 2.36 \\
\hline 18 & 1 & 37.4 & 1.68 & 73.03 & 24.43 & 2.54 \\
\hline 37 & 1 & 37.4 & 1.81 & 74.39 & 23.42 & 2.20 \\
\hline 62 & 1 & 37.4 & 1.83 & 74.85 & 23.13 & 2.02 \\
\hline 92 & 1 & 37.4 & 1.72 & 75.86 & 22.36 & 1.78 \\
\hline 123 & 2 & 29.4 & 1.77 & 63.61 & 33.16 & 3.23 \\
\hline 151 & 2 & 29.4 & 1.73 & 55.15 & 38.84 & 6.01 \\
\hline 180 & 3 & 37.4 & 1.83 & 69.96 & 27.18 & 2.86 \\
\hline 212 & 3 & 37.4 & 1.83 & 88.46 & 10.68 & 0.85 \\
\hline 241 & 3 & 37.4 & 1.82 & 94.58 & 4.98 & 0.44 \\
\hline 257 & 3 & 37.4 & 1.81 & 93.71 & 6.28 & 0.01 \\
\hline \multicolumn{7}{|c|}{ White River Basin, IN } \\
\hline 15 & 1 & 35 & $177^{\mathrm{a}}$ & 23.40 & 49.50 & 27.10 \\
\hline 28 & 2 & 35 & $1.77^{\mathrm{a}}$ & 14.80 & 51.00 & 34.20 \\
\hline 41 & 3 & 35 & $1.77^{\mathrm{a}}$ & 13.90 & 52.80 & 33.30 \\
\hline 53 & 4 & 35 & $1.77^{\mathrm{a}}$ & 16.80 & 50.50 & 30.20 \\
\hline 66 & 5 & 35 & $1.77^{\mathrm{a}}$ & 29.00 & 40.80 & 30.20 \\
\hline 81 & 6 & 35 & $1.77^{\mathrm{a}}$ & 32.10 & 39.30 & 28.60 \\
\hline 97 & 7 & 35 & $1.77^{\mathrm{a}}$ & 31.90 & 45.00 & 23.10 \\
\hline 114 & 8 & 35 & $1.77^{\mathrm{a}}$ & 33.60 & 46.40 & 20.00 \\
\hline 132 & 9 & 35 & $1.77^{\mathrm{a}}$ & 36.10 & 43.90 & 20.00 \\
\hline 145 & 10 & 35 & $1.77^{\mathrm{a}}$ & 39.60 & 42.90 & 17.50 \\
\hline 157 & 11 & 35 & $1.77^{\mathrm{a}}$ & 34.80 & 45.50 & 19.70 \\
\hline
\end{tabular}

${ }^{a}$ Average at site. 
Table 3. Model parameters associated with chemical transport of bromide, atrazine, and atrazine degradates.

[CA, California; IN, Indiana; ppm, parts per million; \%, percent; $\mathrm{mm}^{-1}$, per millimeter; $\mathrm{ml} / \mathrm{g}$, milliliters per gram; $\mathrm{K}_{\mathrm{oc}}$, organic carbon partition coefficient; $\mathrm{K}_{\mathrm{ow}}$, octanol-water partition coefficient; $\mathrm{mm} \mathrm{Hg}$, millimeters mercury; $\mathrm{cm}^{2} / \mathrm{sec}$, square centimeters per second; $\mathrm{cm}$, centimeters; NA, not applicable; NU, not used because atrazine applied before plant germination]

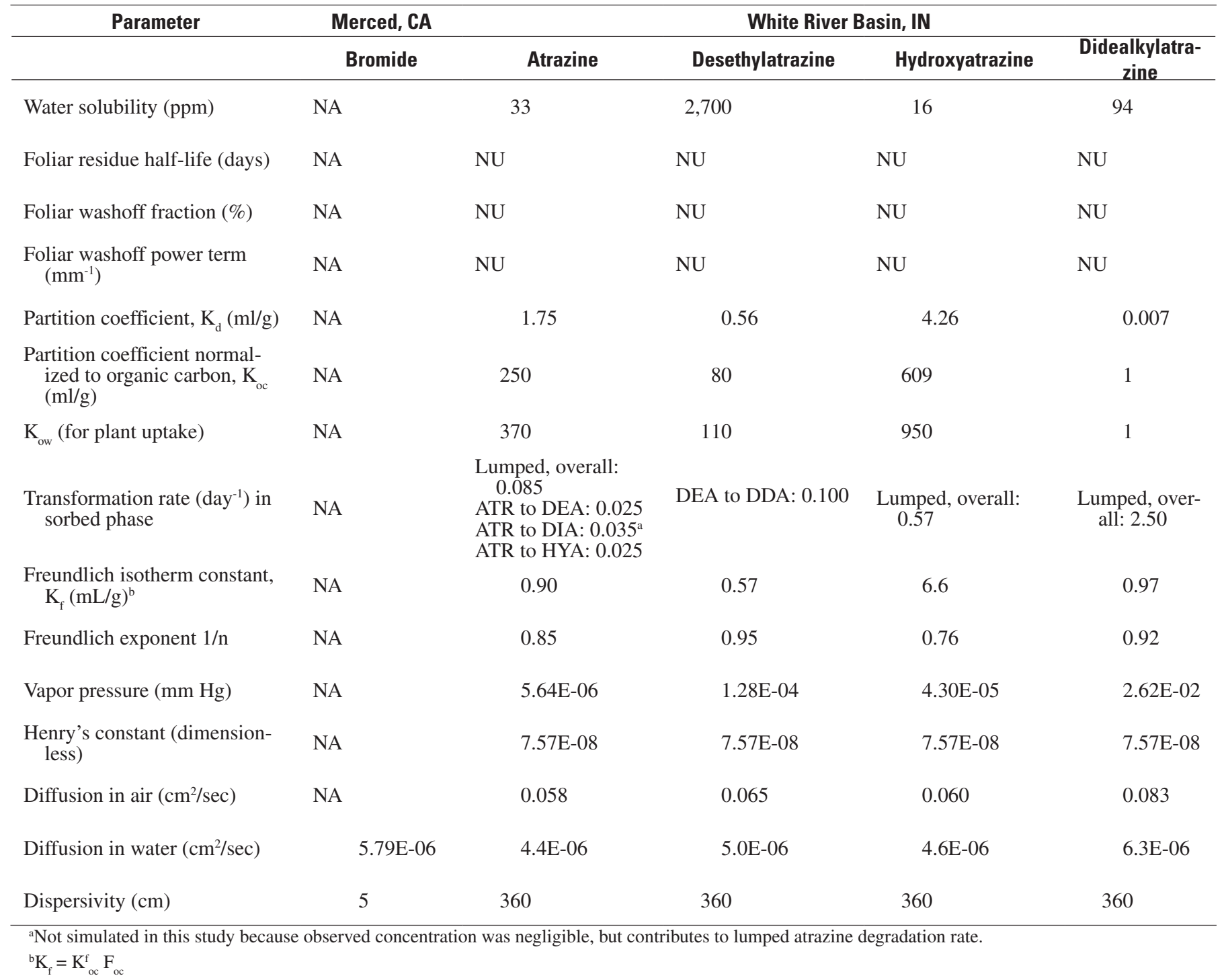

from field rates because in the laboratory, soil samples are disaggregated, pesticide solutions are uniformly mixed, and flow rates are controlled (Ma and Selim, 1996). Additionally, laboratory transport studies rarely include secondary porosity as a dominant feature, or the non-steady interactions of system chemistry and biology.

Because the simulated processes varied from model to model (table 1), each has certain parameters not found in the other models. For example, RZWQM requires inputs for the dimensions of soil cracks and the "average volume fraction of macroporosity." At the White River Basin site, these values were estimated based on soil cracks observed at the ground surface. The macropore option of RZWQM was not used for the Merced site.

The complex models used a variety of characteristic curve functions to specify the relations between moisture content, matric pressure, and hydraulic conductivity. The van Genuchten (1980) function was used for HYDRUS and VS2DT. For Merced, VS2DT simulations used a modified version of the van Genuchten function that included separate curve-fitting parameters for retentivity and conductivity (Healy and Ronan, 1996). LEACHP and RZWQM used Campbell's (Hutson, 2003) and Brooks-Corey functions (Ahuja and others, 2000), respectively.

Parameters were derived for every combination of sediment layer (table 2) and characteristic curve function for both sites. For Merced, the van Genuchten retention function was fitted to field-measured moisture content and matric pressure, and the conductivity function was fitted to laboratory-measured moisture content and unsaturated hydraulic conductivity. For the White River Basin, grain-size data were used with the 
U.S. Department of Agriculture's (USDA's) Rosetta model (Schaap and others, 2001) to estimate parameters of the 1980 van Genuchten function for each sediment layer. For both sites, parameters of Campbell's and Brooks-Corey functions were optimized using the Solver tool in Microsoft Excel to achieve characteristic curves as similar to the van Genuchten functions as possible. Figure 1a shows the fit of the van Genuchten function for sediment type 1 at Merced, CA. An example of the Brooks-Corey function fitted to van Genuchten values from the White River Basin (1.45 meters $(\mathrm{m})$ ) is shown in figure $1 \mathrm{~b}$. To construct the plots, the sign convention of matric pressure was reversed and the resulting positive values (in centimeters) were log transformed. Moisture contents at field capacity $(330 \mathrm{~cm})$ and wilting point $(15,000 \mathrm{~cm})$ were taken from the van Genuchten curves to parameterize the simple models.

Initial conditions of pressure and solute concentration were specified for each of the two test sites. Initial pressure was set for Merced based on field data using a linear function that ranged from $-800 \mathrm{~cm}$ at $0 \mathrm{~cm}$ depth to $-200 \mathrm{~cm}$ at $600 \mathrm{~cm}$ depth. The initial pressure for White River Basin was set to a constant value of $-10 \mathrm{~cm}$. For White River Basin, a 1-month period prior to the application of pesticides was simulated to establish initial conditions for solute transport. All solute concentrations were initially set to zero at both sites.

Top boundary conditions consisted of weather and chemical inputs to the different models. In general, the upper boundary alternated between specified flux (infiltration) and modelcomputed evapotranspiration. Precipitation records from the closest daily-measured raingage were used to calculate the total rainfall and timing of rain events. In VS2DT, infiltration was applied at a constant rate equal to the mean rainfall rate for the study period. The duration of infiltration was adjusted to apply the correct amount of precipitation for each rainfall event. In the remaining models, daily rainfall was entered. In

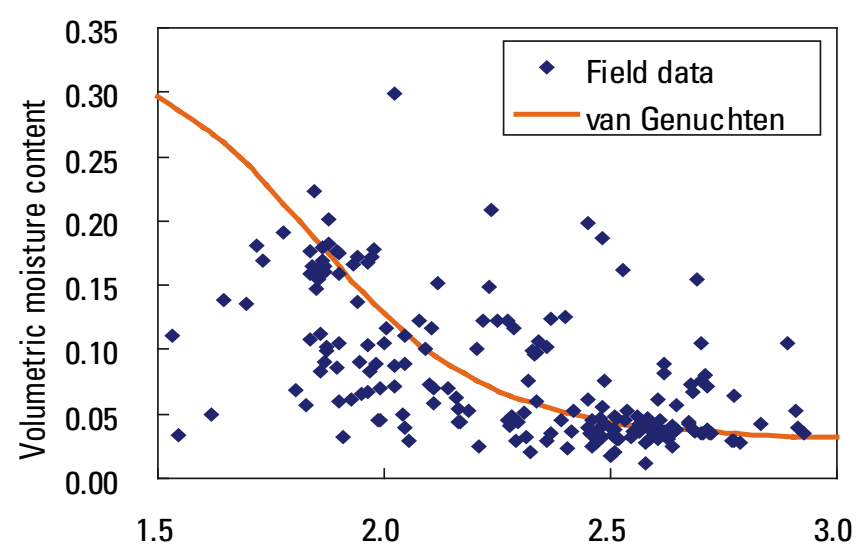

Log matric pressure, in centimeters $(\mathrm{cm})$

Figure 1a. Fit of van Genuchten moisture-retention function to field data at Merced, California, for sediment type 1 $10-125 \mathrm{~cm}$ and $175-300 \mathrm{~cm}$ depths). Parameters of the van Genuchten function for sediment 1 are: $\theta_{r}=0.03 ; \varphi=0.322 ; \beta_{2}=2.813 ; \alpha=0.017$; where $\theta_{r}=$ residual moisture content, $\varphi=$ porosity, and $\alpha$ and $\beta_{2}$ are water-retention parameters. general, daily precipitation and irrigation records were used to calculate the total infiltration while solar radiation, wind movement and dew point data were required to calculate evapotranspiration.

Bottom boundary conditions were specified according to the capabilities of the models. In particular, LEACHP was stable with White River Basin data only when water-table depth was fixed at the bottom of the soil profile. For all of the models, constant matric potential was specified and set at $-280 \mathrm{~cm}$ for Merced (6 $\mathrm{m}$ depth) and $0 \mathrm{~cm}$ for the White River Basin (2.5 m depth).

\section{Results}

Differences between observed and simulated values can result from inappropriate parameter values or lack of the model's ability to simulate processes occurring at a site. Although the models in this study were not calibrated to field data, differences in model output can shed light on model capabilities. The following observations are based on visual assessment of model fit compared with observed values of moisture content, matric potential, and/or chemical concentrations. Moisture content, matric potential, and bromide concentration were measured at the Merced site; matric potential and concentrations of atrazine and degradates were measured for the White River Basin site.

\section{Merced, CA}

Moisture-content profiles generated by complex models generally agreed with observed values at depths to about $120 \mathrm{~cm}$ (fig. 2). Below this depth, LEACHP and RZWQM

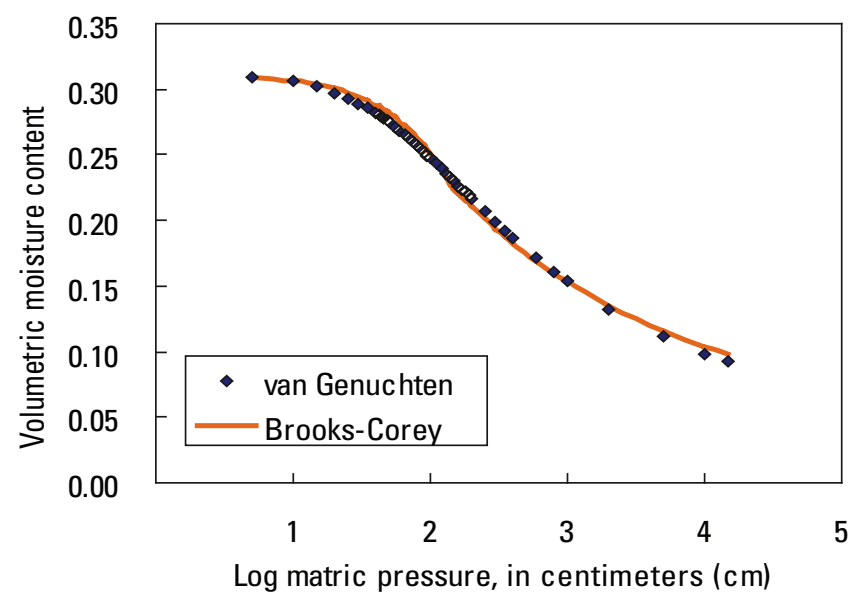

Figure 1b. Fit of Brooks-Corey moisture-retention function to van Genuchten values derived from grain size data at the White River Basin (1.45 meters). Parameters of the Brooks-Corey function for this sediment layer are: $\theta_{r}=0.043 ; \theta_{s}=0.316 ; A_{i}=0.000614$ $\mathrm{cm} ; \lambda=0.262 ; \mathrm{B}=0.672$; where $\theta_{\mathrm{r}}=$ residual moisture content, $\theta_{\mathrm{s}}$ $=$ saturated moisture content, and $A_{i^{\prime}} \lambda$, and $B$ are curve-fitting parameters. 


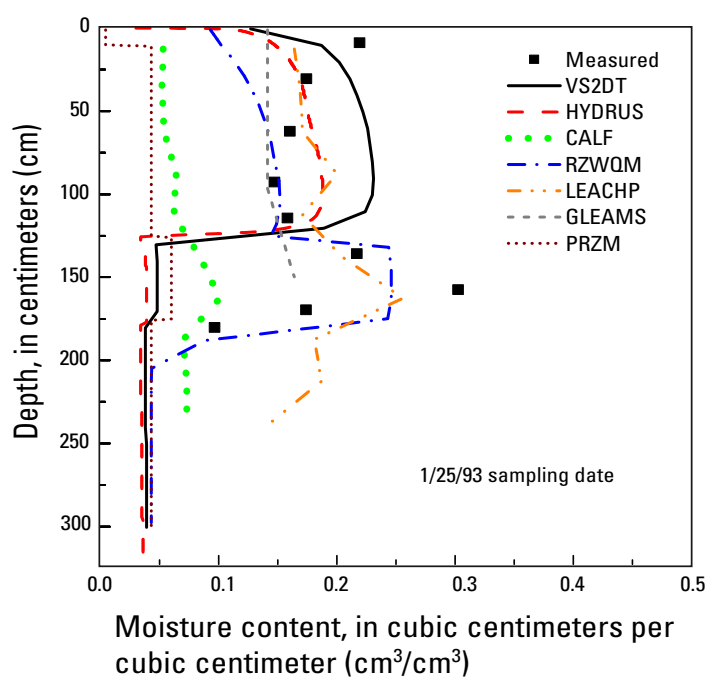

Figure 2. Moisture content with depth at Merced, California.

more closely approximated the observed profiles, whereas HYDRUS2D and VS2DT predicted drier conditions than observed. CALF and PRZM generally predicted lower moisture content than observed, which may have resulted from moisture contents at field capacity $(0.04-0.06)$ and wilting point (0.03) used as input to the tipping-bucket models. Although these values seem low, they correspond to an empirically derived water-retention curve for the Merced site.

GLEAMS predictions stopped at $150 \mathrm{~cm}$ because that is the maximum simulation depth for this model. Also, GLEAMS does not estimate soil moisture per se, but does provide "soil water depth by layer" in centimeters. These values were converted to tons of water and divided by the tons of soil in each layer to produce the GLEAMS output in fig. 2.

HYDRUS2D, LEACHP, RZWQM, and VS2DT adequately simulated matric potential to about $125 \mathrm{~cm}$ depth (fig. 3 ); CALF predicted lower potentials than observed at shallow depths. HYDRUS2D, RZWQM, and VS2DT predicted

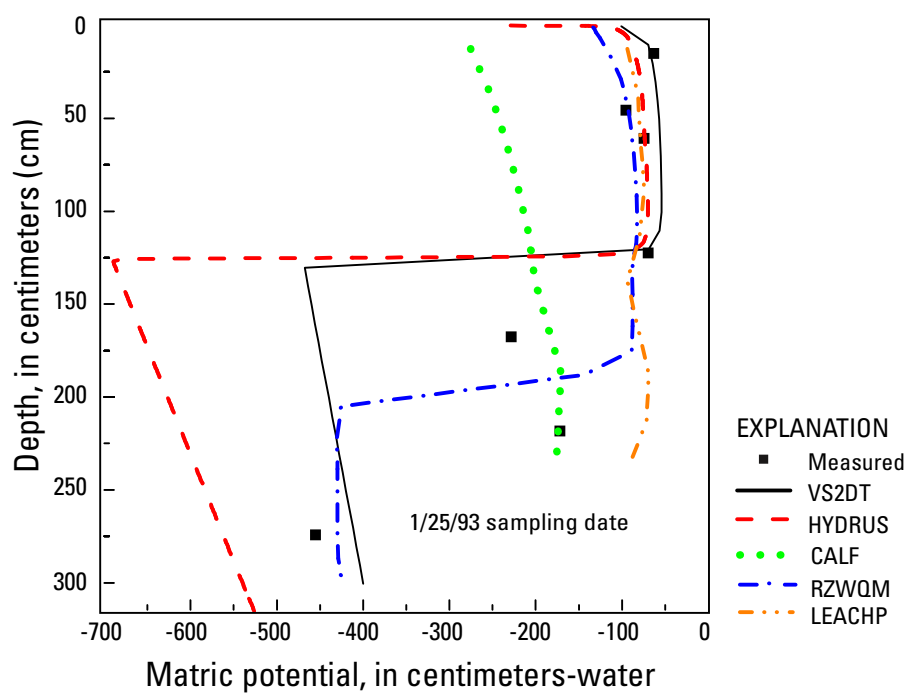

Figure 3. Matric potential with depth at Merced, California. decreasing (i.e., more negative) matric potential below 125 $\mathrm{cm}$, which is consistent with the observed values. The low pressures at depth are below the wetting front and result from drainage and evapotranspiration (ET) during the dry spring and summer months preceding the tracer test. LEACHP, a complex model, predicted nearly constant matric potential (about $-100 \mathrm{~cm}$ ) with depth.

Bromide tracer was applied to the soil surface at Merced on August 20, 1992. On January 25, 1993, observed bromide concentrations at Merced were bimodal, with some of the mass retained at the soil surface (less than $50 \mathrm{~cm}$ ) (fig. 4). A deeper observed peak exists at about $160 \mathrm{~cm}$. Using a mobile-immobile feature, HYDRUS2D simulated both peaks, although the predicted peak concentration of mobile bromide is shallower than observed. The mobile-immobile feature simulates non-equilibrium solute transport by separating the liquid phase into mobile (flowing) and immobile (stagnant) zones, and solute exchange between the two zones is modeled as a first-order process (Šimůnek and others, 1999). RZWQM predicted a single peak at depth that lagged slightly behind the observed values. LEACHP predicted that the peak bromide concentration occurred near the soil surface. Simple models generally underpredicted bromide concentration at depth. PRZM predicted the lowest bromide concentrations (less than 1 milligram per kilogram (mg/kg)); concentrations increase below about $300 \mathrm{~cm}$, indicating that most of the simulated bromide peak has already passed through the model profile. GLEAMS simulated a concentration peak of approximately 3 $\mathrm{mg} / \mathrm{kg}$ at the $100 \mathrm{~cm}$ depth.

\section{White River Basin, IN}

HYDRUS2D, VS2DT, RZWQM, and LEACHP simulated matric potential in the White River Basin fairly accurately (fig. 5). RZWQM predictions of matric potential decreased (became more negative) after day 250, but there were no observed values at later times for comparison. CALF

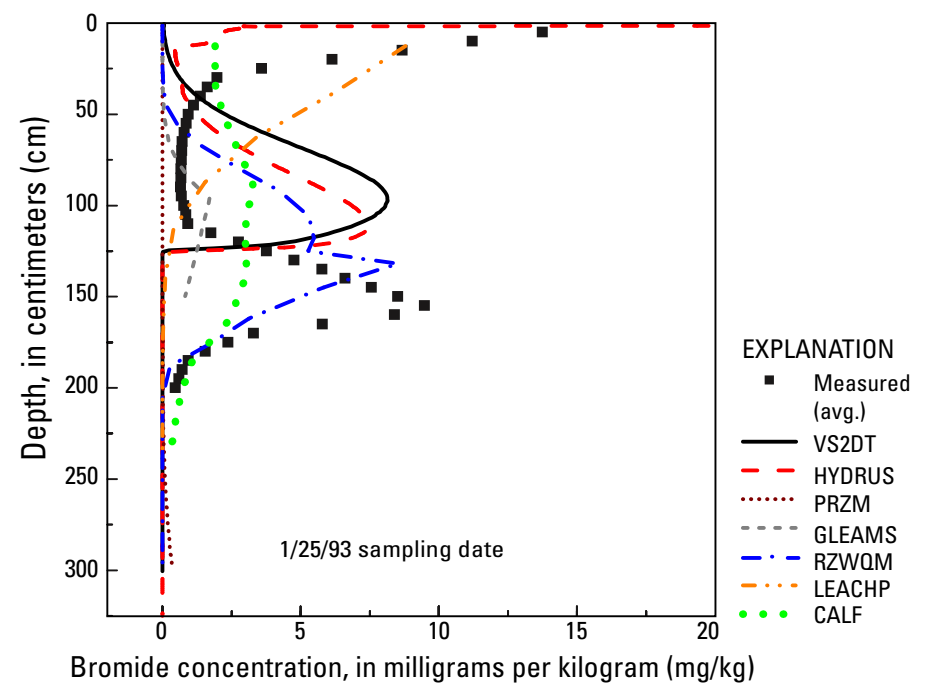

Figure 4. Bromide concentration with depth at Merced, California. Units are milligrams per kilogram of soil dry weight. 


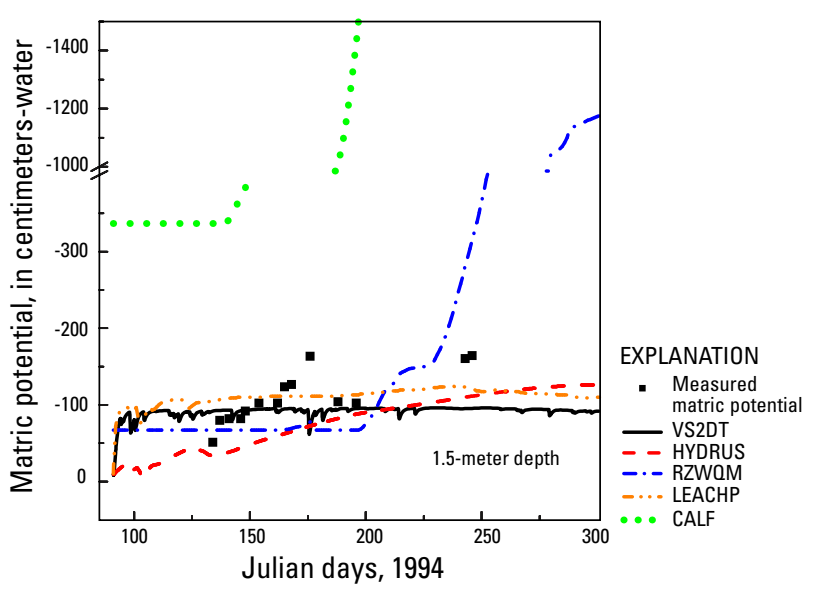

Figure 5. Matric potential with time at White River Basin, Indiana.

predictions were consistently lower (more negative) than observed values. PRZM and GLEAMS do not simulate matric potential.

Atrazine was applied on April 18, 1994 (Julian day 118), at monitoring site C. Bayless (2001) previously argued on the basis of field observations and modeling results that preferential flow is important at this site. Use of the macropore option in RZWQM with no dispersivity predicted the rapid arrival of atrazine at the 150-cm sampling depth (fig. 6). RZWQM also simulated atrazine concentration fairly well at later times (150 days or more). Although they do not simulate macropore flow, HYDRUS2D accurately simulated the rapid arrival of atrazine, and VS2DT predicted atrazine arrival just a few days ahead of observed values. The rapid transport probably resulted from the comparatively large dispersivity value used for these simulations $(360 \mathrm{~cm})$. High dispersivity values cause the leading edge of a simulated solute plume to arrive earlier, increasing the simulated concentration at the observation point. The high dispersivity value was taken from a prior modeling study in the area (Bayless, 2001). Atrazine concentrations predicted

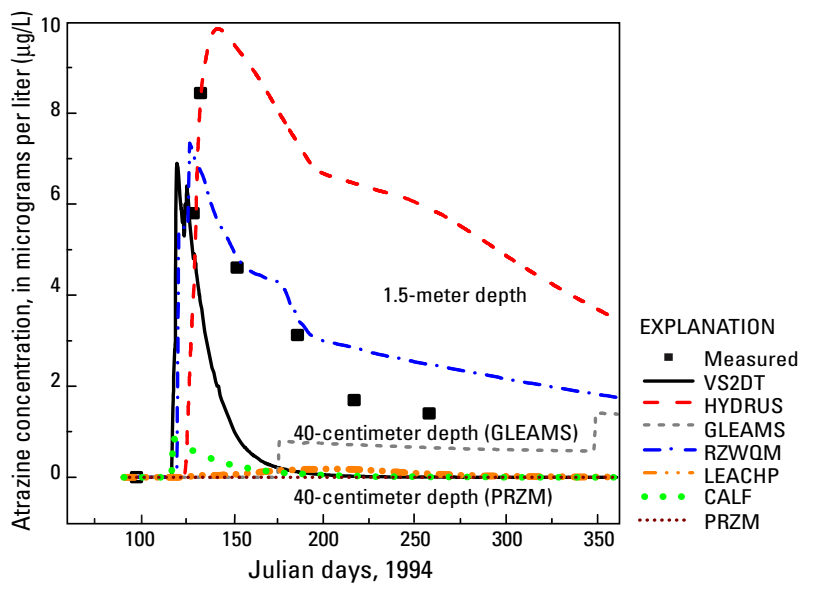

Figure 6. Atrazine concentration with time at White River Basin, Indiana. Atrazine applied on April 28, 1994 (Julian day 118). Units are micrograms per liter of water. by HYDRUS2D are two to three times observed values after 150 days. Simulation results from GLEAMS and PRZM are presented in figures 6-8 for a depth of $40 \mathrm{~cm}$, rather than 1.5 $\mathrm{m}$, because both models predicted negligible concentrations of atrazine and degradates at $1.5 \mathrm{~m}$ throughout the simulation period.

HYDRUS2D simulated DEA concentrations fairly accurately up to about 160 days, after which predicted concentrations were about twice the observed values (fig. 7). RZWQM simulated DEA concentrations fairly accurately after about 200 days. All other models (excluding VS2DT, which does not simulate conversion to degradates) underpredicted DEA concentrations. PRZM predicted extremely low DEA concentrations at $40 \mathrm{~cm}\left(10^{-7}\right.$ micrograms per liter ( $\left.\mu \mathrm{g} / \mathrm{L}\right)$ or less), which might be related to a problem with the grid cell size. The grid spacing was 1-millimeter $(\mathrm{mm})$ layers up to $10 \mathrm{~cm}$, and $1-\mathrm{cm}$ layers at depths greater than $10 \mathrm{~cm}$, as suggested by the PRZM documentation. Grid cell size influences simulated numerical dispersion in PRZM, such that the smaller the cell, the lower the dispersion, especially for a strongly sorbing and decaying solute. Alternatively, increasing numerical dispersion by increasing grid size would accelerate the movement of the leading edge of solute and increase simulated concentrations at the observation point.

All models for which DDA output was available consistently underpredicted the observed concentrations (fig. 8). CALF output for DDA was unstable and included negative values; however, prior simulations with CALF accurately simulated atrazine, DEA, and DDA at the White River Basin site (Bayless, 2001). The current study used values of moisture content at field capacity and wilting point from an empirically derived water-retention curve, to provide consistent estimates for models that use different water-retention functions. These values differed from values used previously in the White River Basin and might have adversely affected CALF predictions. Testing of CALF and LEACHP included tracking a second daughter product of atrazine (HYA), but the predicted concen-

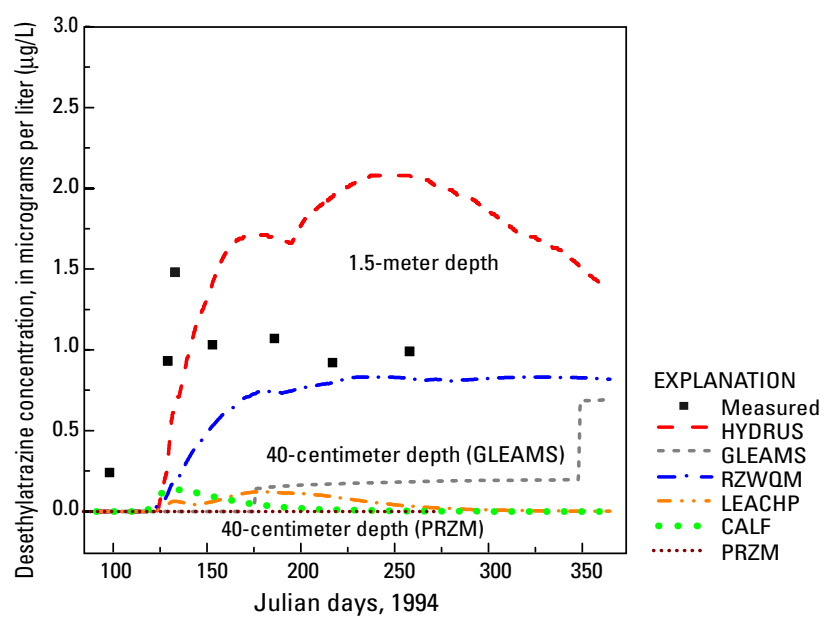

Figure 7. Desethylatrazine concentration with time at White River Basin, Indiana. Atrazine applied on April 28, 1994 (Julian day 118). Units are micrograms per liter of water. 


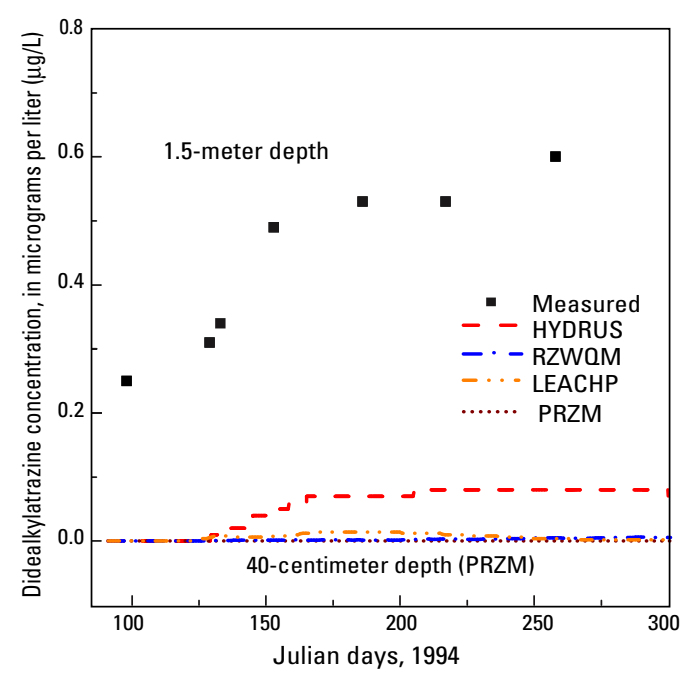

Figure 8. Didealkylatrazine concentration with time at White River Basin, Indiana. Atrazine applied on April 28, 1994 (Julian day 118). Units are micrograms per liter of water.

trations are consistently less than $0.005 \mu \mathrm{g} / \mathrm{L}$; therefore, HYA results are not plotted.

\section{Model Summaries}

The five modelers conducting these simulations have provided a brief summary of each model, based on their experiences with the two data sets. The summaries emphasize general model capabilities and key strengths and weaknesses that emerged during these evaluations. Advantages and disadvantages of each model are discussed first for the complex models (LEACHP, HYDRUS2D, RZWQM, and VS2DT), and then for the simple models (CALF, GLEAMS, and PRZM).

\section{Complex models}

\section{LEACHP}

\section{Advantages}

The Leaching Estimation and Chemistry Model (LEACHM) is a DOS-based, modular model for independently simulating transport of heat, inorganic chemicals, pesticides, and nutrients in the unsaturated zone. The LEACHP (Leaching Estimation and Chemistry Model for Pesticides) module of LEACHM simulates pesticide transport using Richards' equation for water flow in the unsaturated zone. Input data are entered into a single file that can be edited with any line editor (vi, Notepad, etc.). The input file is logically arranged and includes extensive comments; users can see all data entered for a single simulation in one long page, as opposed to the multiple files, windows, and menus that were used in the other codes tested. LEACHP has no databases to supply input information; however, demonstration input files are supplied for each module. LEACHP can estimate characteristic curve and unsaturated conductivity functions from grain-size data or can utilize user-supplied parameters for the Campbell equation. LEACHP can simulate up to eight pesticides separately or in degrading succession. The LEACHM/LEACHP code and documentation are available for free at $h t t p: / / w w w . s c i e n g$. flinders.edu.au/cpes/people/hutson_j/leachweb.html (accessed on December 16, 2003).

\section{Disadvantages}

The modularity (and simplicity) of the LEACHM code makes it user friendly, but also results in exclusion of some processes and environmental data that have bearing on pesticide fate and transport simulations. For example, the capacity version of LEACHM divides water into mobile and immobile zones, but it is not a true dual-porosity model because the two zones cannot be independently controlled; and, the model excludes pesticides and soils databases. LEACHM pays limited attention to farm-management practices and crop development. Simulations of nutrient and organic-residue distribution and inorganic soil and water chemistries can be examined in other LEACHM modules; however, because those modules are uncoupled from the LEACHP module, their influence on pesticide fate cannot be directly simulated. Similarly, water flow in LEACHP is simulated entirely by solution of the Richards' equation; a macropore simulating module, CALF, is part of the LEACHM code but executes as a stand-alone module (see below). There is no graphical output of LEACHP results and this slows down manual calibration. LEACHP does not have built-in capability to perform parameter estimation or uncertainty analysis.

\section{HYDRUS2D}

\section{Advantages}

HYDRUS2D has extensive capabilities for process-oriented modeling. Because the model is fairly extensive, it may require a bit more time to learn than other models. Available documentation consists of help within the graphical user interface (GUI), and a manual (available online). The help files for the program are indexed and searchable, but only cover the basics of the model GUI and parameter set. More extensive information is available within the manual, which is not searchable. User forums and a list of frequently asked questions are available online at http://www.pc-progress. cz/Fr_Hydrus.htm (accessed on January 22, 2004).

There are two versions of HYDRUS: HYDRUS1D and HYDRUS2D. The one-dimensional (1-D) version is available online for free. The model simulates nearly identical processes as the 2-D version, with some added features. The solution time is faster for 1-D problems and the developers suggest that the 1-D version is more appropriate for certain types of problems than the $2-\mathrm{D}$ version. The $2-\mathrm{D}$ version is available 
for nominal cost, but the optional grid generator, which is important for complex 2-D problems, does cost extra. The site licensing policy, however, is that three individual licenses at one site constitute a site license, and additional copies of the model are free. The GUI's of the two versions are nearly identical, and if a user knows one version, the other will be easy to use.

HYDRUS2D has many features that may not be available in other Richards' equation-based models. For example, there are options to automatically calculate a tortuosity factor for the diffusion coefficient, an option to simulate hysteresis in the retention curves, and options to include physical, non-equilibrium in solute transport (mobile-immobile zones). Additionally, HYDRUS2D has coupled heat and water transport capability. These features may be helpful for testing conceptual models of solute transport.

HYDRUS2D has built-in soil catalogs with default parameters for different soil types. There is also an option of using neural network predictions to get Rosetta estimates of water retention parameters and hydraulic conductivity. HYDRUS2D has a database of suggested values for root water uptake for different plants, and most of the common crops are included in this database.

The output graphics are clear and include 2-D, X-Y graphs, contour maps, and spectral maps. These can appear on-screen or be exported as images. It is also possible to get graphs of any variable along an arbitrary line across the model domain.

Additional strengths of the model include: convenient input for precipitation and ET on a daily basis; a user-friendly GUI; tabular outputs of retention and conductivity curves; calculations of mass budgets in arbitrary regions at any depth; flexible and robust characteristic curve models; ability to simulate five solutes either independently or in a reaction chain; and built-in inverse modeling capability.

\section{Disadvantages}

HYDRUS2D has several limitations. The assignment of boundary conditions is a little complicated and confusing. For a given node, the assigned boundary type cannot change during a single simulation. For example, an atmospheric boundary node (which is able to switch between ET and precipitation) cannot change to a seepage face.

When HYDRUS2D does not converge, it often returns a floating point error with no explanation. Resolution of problems with convergence was sometimes time consuming and awkward.

Time-step control parameters in the model are set for the entire simulation and not for each specified variable boundary condition period. Sudden changes in conditions (e.g., heavy rain following a prolonged dry period) may require manipulation of the boundary conditions (e.g., spreading out the rain over a longer period) to get the model to converge.

HYDRUS2D can track five solutes, but the degradation pathways must be in linear degradation sequences. Thus, the model cannot simulate more than one daughter of the parent compound in the same simulation.

Finally, the root water uptake information is based on a single crop-growing season. If the simulation period includes more than one crop cycle, the model needs to be run as successive simulations. The model does not allow time-variable root spatial distribution.

\section{RZWOM}

\section{Advantages}

Root Zone Water Quality Model (RZWQM) is a multiprocess, Windows-compatible program for simulating heat, nutrient and pesticide transport in the unsaturated zone under agricultural influence. Soil heat flux during water redistribution is calculated with an equation that includes terms for diffusive transport, convective heat transport by liquid, and latent heat transfer by vapor. Heat advection during infiltration events is simulated with a separate heat balance equation. Three input files for climate data must be created prior to model execution. The climate files can be auto-generated, based on probabilistic analysis of long-term historical records from meteorological stations, or the user can create them from on-site measurements. All other information relevant to the simulations is entered through drop-down menus. Pesticideproperty, farm-management, and crop-development databases can provide default information where measured data are unavailable.

The model is very flexible with the ability to simulate more agricultural processes than any other code tested. A fully integrated, physically based macropore-simulation capability is a fairly unique property of RZWQM. The model has the ability to simultaneously simulate transport of three pesticides, which may include a parent-daughter-granddaughter succession. RZWQM contains modules to simulate overland flow, sediment routing, tile drainage, inorganic water and soil chemistry (which can effect pesticide properties), and microbial activity stimulated by organic residue.

Model output includes sophisticated 2-D and threedimensional (3-D) plots of time-dependent input and output variables that can be viewed on screen or saved in bitmap and metafile formats. Results are also output in user-specified tabular files. The model is well documented in online indexing and contents windows, and has an accompanying text: Root Zone Water Quality Model - Modeling Management Effects on Water Quality and Crop Production (Ahuja and others, 2000). The RZWQM code is available for free from the U.S. Department of Agriculture-Agricultural Research Service (USDA-ARS) at http://gpsr.ars.usda.gov/products/rzwqm.htm (accessed in January 2004).

\section{Disadvantages}

The complexity of the model results in more parameters and, therefore, greater data-input needs. A parameter estima- 
tion and uncertainty analysis package would be a welcome addition. The crop-development database is incomplete. In the tested version of the code, the maximum simulation depth was $3 \mathrm{~m}$; but this has since been extended to $30 \mathrm{~m}$ by the USDAARS. RZWQM cannot easily simulate macropore flow in dry, sandy soils, because the model requires ponding and overland flow to induce macropore flow. Macropore flow, however, can be induced in sandy soils by specifying a surface crust with a low hydraulic conductivity. There is no user-defined dispersivity in RZWQM. Mechanical dispersion (function of dispersivity) is simulated for mobile water by two-stage, partial piston displacement, and molecular diffusion (the other component of hydrodynamic dispersion) is explicitly included and parameterized by the user (Ahuja and others, 2000). Alternatively, the scale relation with dispersivity can be simulated with numerical dispersion. The RZWQM reference text (Ahuja and others, 2000) is not free, but can be purchased from Water Resources Publications, Inc.

\section{VS2DT}

\section{Advantages}

Variably Saturated Two Dimensional Transport (VS2DT) is a suitable model for simulation of unsaturated flow and transport under many circumstances. The GUI is relatively straightforward and easy to use. Basic help is available from within the GUI. Printed documentation includes the original manual for VS2D (flow only), the manual for VS2DT and VS2DH (solute and heat transport, respectively) and a manual for the GUI. All are free, but only the GUI manual is available in electronic form.

The main advantages of VS2DT are that it is simple to use and easy to learn. The model itself is free and available online from http://water.usgs.gov/software/vs2di.htm (accessed on January 22, 2004). Several example problems are included with the code to acquaint the user with the GUI. When the pre-programmed characteristic curve models are not adequate for a user's needs, any shape of characteristic curve can be modeled by using the tabular data input option. Another feature of the model is the flexibility of boundary conditions and iteration parameters. The assigned boundary type can be changed for any cell at any time. Likewise, the iteration parameters are assigned for each recharge period, so that the user can assign smaller time steps when there is a sudden change in conditions (e.g., rainfall after a prolonged dry spell). Root depth and activity can also be varied with time. VS2DT has built-in databases with textural classes and new classes can be imported from text files. The model has 22 generic soil types with default parameters for these types.

The VS2DT GUI has runtime graphics to show various output variables, and the graphs at any instant can be exported and saved as bitmaps. Also, text files with the output data can be imported into graphics packages such as Excel.

\section{Disadvantages}

The model tracks a single compound and cannot simulate the formation, transport, and fate of degradates. Preferential flow can be simulated by adjusting $\mathrm{K}_{\text {sat }}$ or by using a bimodal retention function entered via tabular data, but there is no option to simulate storage in immobile zones. There is no built-in option to simulate hysteresis. As compared to HYDRUS, VS2DT has fewer features such as built-in databases, parameter estimation routines, and options for graphical display of results.

The current version of VS2DT has no cut and paste option for the GUI, and all entries must be entered manually. For simple scenarios this may not be an issue, but for a scenario with 300 recharge periods, the GUI is impractical. Typically, a user can use the GUI for much of the problem, but then must edit the text input file to enter a lengthy list of recharge period information.

VS2DT cannot have precipitation and evaporation occurring simultaneously in the same recharge period. Average rainfall intensity is needed to predict the duration of each rainfall event and following evapotranspiration event. Although the quality of output graphics is good, the scale does not automatically adjust to accommodate changing values such as pressure and concentration during a simulation.

\section{Simple models}

\section{CALF}

\section{Advantages}

The CALculates Flow, leaching of pesticides in field soils (CALF) model is an option within LEACHM (the family of models that includes LEACHP) that simulates water flow using a tipping-bucket approach, and is intended to represent macropore transport of pesticides. Input data are entered into a single file that can be edited with any line editor (vi, Notepad, etc.). Similar to LEACHP, the strength of CALF is the simplicity of the data input file, which is logically arranged and wellcommented; users can see all data entered for a simulation in a single file. CALF contains no databases to supply input information, however, a sample input file is provided with the code and documentation. CALF can examine the transport of up to eight pesticides or pesticide transformation compounds. A single toggle switches from CALF to LEACHP, making it easy to examine transport by the two water-flux algorithms.

\section{Disadvantages}

CALF is a simple model in concept and was able to simulate atrazine, DEA, and HYA in the current study. CALF output for DDA was unstable and included negative values. This was not considered overly limiting, however, because CALF accurately simulated atrazine, DEA, and DDA at the same site in an earlier study (Bayless, 2001). 
The model is limited to linear sorption and is strongly affected by the user-specified field capacity. Like LEACHP, there are no graphic outputs and plotting data must be extracted from tabular files. The uncoupled solution of Richards' equation (LEACHP) for flow in the soil matrix and the Addiscott option for preferential flow makes interpretation of results difficult because, under field conditions, these processes can occur simultaneously. CALF does not have built-in code to perform parameter estimation or uncertainty analysis.

\section{GLEAMS}

\section{Advantages}

Groundwater Loading Effects of Agricultural Management Systems (GLEAMS) is a DOS-based continuous simulation, field-scale, modular model based on the Chemicals, Runoff and Erosion from Agricultural Management Systems (CREAMS) model. GLEAMS is incorporated into USDA's Soil and Water Assessment Tool (SWAT) watershed model, which facilitates simulation of UZ processes to watershed scales. GLEAMS is relatively simple to learn, and simplified DOS-based GUI files ease the building of text input parameter files for the hydrology, erosion, nutrient, and pesticide modules. The erosion module is comprehensive, allowing the detailed input of the topographic features of an area for use in predicting sediment yield. A total of 366 pesticides can be simulated simultaneously and a pesticide parameter database provides information for 336 possible chemicals. Application running time is not a concern, averaging a few seconds per simulation and running efficiently with few unnatural terminations during simulations. Output is available for a number of different daily, monthly, and annual variables in both standard and metric units, for both calibration and display purposes.

\section{Disadvantages}

Climate data files for daily temperature and precipitation require a specific format that is tedious to produce for model simulations. All other climate data are entered as monthly averages. Some parameters, including saturated hydraulic conductivity and porosity, are limited to intervals specified in the input module GUI. Simulation conditions are limited to five soil horizons and confined to the root zone, which is limited to a maximum depth of $1.52 \mathrm{~m}$. Irrigation estimates can be calculated using an internal process that balances soil-moisture values, but will not allow for the input of specific irrigation values. The inclusion of these irrigation totals within precipitation values allows for a possible spike in runoff that would not occur during normal irrigation practice. While the pesticide and nutrient modules of the application can be excluded from the simulation, the erosion module is mandatory for each simulation, which may be beyond the desired scope of the project. Simulation output is available for many different variables, but some common variables such as soil moisture and matric pressure are absent.

\section{PRZM}

\section{Advantages}

The Pesticide Root Zone Model (PRZM) is capable of simulating complex scenarios such as the metabolic activity of microbial populations, pesticide application techniques, erosion, runoff, plant uptake, and agricultural-management practices. PRZM also simulates pesticide decay in the dissolved, adsorbed, and vapor phases. There is no maximum limit for depth of simulation, and the ability to vary horizon thickness is useful for representing detailed soils data. PRZM produces time-series data of fluxes at a given point in the soil profile in columnar, ASCII format that can be processed fairly quickly.

\section{Disadvantages}

Model output is extremely sensitive to horizon (grid cell) thickness, which is arbitrarily set by the model user. Model documentation provides minimal guidance on selection of the number and thicknesses of horizons.

The user's manual is sometimes difficult to follow and focuses more on theory than on practical guidance in using the model. Although there is extensive discussion of theory, it is sometimes unclear how or whether the model simulates the processes being described. PRZM was written in FORTRAN in the early 1980s and uses formatted ASCII files for input. As a consequence, learning how to set up and operate PRZM can be difficult. For example, learning how to format the main input file can be time consuming.

\section{Summary}

Seven unsaturated-zone contaminant-transport models were compared for ease of use and model capabilities. The models were tested with two data sets in cold simulation mode. Proper calibration was beyond the scope of the study, but differences in model output provided insights into important differences in model capabilities.

Among complex models, RZWQM, HYDRUS2D, and VS2DT were the easiest to use because of user-friendly GUIs and extensive documentation. Of these, RZWQM and HYDRUS2D can simulate several parent compounds and degradates. RZWQM can explicitly simulate water and solute flux in macropores, a potentially important feature for sites with structured soils. Both HYDRUS2D and VS2DT can simulate water and solute flux in two dimensions, which might be needed at sites near streams or drains. Although the tested version of RZWQM has a maximum simulation depth of 3 $\mathrm{m}$, the USDA-ARS has since extended this depth to $30 \mathrm{~m}$. VS2DT simulates the transport and fate of a single compound. Although LEACHP has no GUI, it is logically arranged and relatively easy to use. The Richards' equation version, however, lacks preferential flow capability. 
Considering all models, only HYDRUS2D predicted both surface-retention of bromide and the deeper peak at the Merced, CA site, based on a mobile-immobile water-flow simulation. RZWQM cannot easily simulate macropore flow in dry, sandy soils, because the model requires ponding and overland flow to induce macropore flow. RZWQM predictions of atrazine (White River Basin) were closest to the measured values. RZWQM simulated macropore flow at this site, which is wetter than the Merced site and has heavily structured soils with visible surface cracks.

Simple models can be used for scale-up and mass balances at the stream-basin scale. Among simple models, CALF (the tipping-bucket version of LEACHP) is simple in concept and easy to use, and has preferential flow capability. GLEAMS is easy to use, simulates effects of agricultural practices, and is incorporated into USDA's Soil and Water Assessment Tool (SWAT) watershed model. GLEAMS, however, has a maximum simulation depth of $1.5 \mathrm{~m}$, and the authors are unaware of any plans to extend it. The depth limitation creates a potential disconnect, for mass balance purposes, between unsaturated-zone transport and the water table. PRZM has no depth limitation and can simulate a variety of processes, including microbial population growth, plant uptake, and agricultural-management practices. PRZM, however, can be difficult to use and the documentation is hard to follow. Additionally, PRZM is sensitive to numerical grid-cell thickness, which determines effective dispersivity.

Among tipping-bucket models, CALF predicted the highest values of atrazine and DEA at the measurement depth of $1.5 \mathrm{~m}$ at the White River Basin site. CALF includes the Addiscott flow option for preferential flow, and also accepts user-specified dispersivity. GLEAMS and PRZM predicted negligible concentrations of atrazine and degradates at a depth of $1.5 \mathrm{~m}$. Low pesticide concentrations predicted by PRZM apparently resulted from the numerical layering scheme (1 $\mathrm{mm}$ in the upper $10 \mathrm{~cm}$ of soil and $1 \mathrm{~cm}$ at greater depths). Increasing dispersion (via grid size in this case) would accelerate movement of the leading edge of solute and would increase simulated concentrations at the observation point.

The unsaturated-zone model evaluation provided insights into model capability and potential shortcomings. Capabilities assessed include the number of dimensions, macropore flow, multiple compounds, and GUIs. For some models, clear limitations in simulation depth, effects of grid cell size, and GUIs for input and output were found. In general, the study permitted evaluation of these factors in the context of anticipated modeling needs for the unsaturated-zone component of NAWQA ACT studies.

\section{References}

Ahuja, L.R., Rojas, K.W., Hanson, J.D., Shaffer, M.J., and Ma L., 2000, Root zone water quality model: Water Resources Publications, LLC, Highlands Ranch, Colorado, 372 p.
Bayless, E.R., 2001, Atrazine retention and degradation in the vadose zone at a till plain site in central Indiana: Ground Water, v. 39, no. 2, p. 169-180.

Carsel, R. F., Smith, C. N., Mulkey, L. A., Dean, J. D., and Jowise, P., 1984, User's Manual for the Pesticide Root Zone Model (PRZM): U.S. Environmental Protection Agency, EPA/600/3-84-109, Athens, Georgia.

Center for Exposure Assessment Modeling [CEAM], 1998, PRZM3: Pesticide Root Zone Model-Release 3, Version 3.12: USEPA Center for Exposure Assessment Modeling, Athens, Georgia. Variously paged [PDF files available for individual chapters].

Dubus, I.G., Beulke, S., and Brown, C.D., 2002, Calibration of pesticide leaching models: critical review and guidance for reporting: Pesticide Management Science, v. 58, p. 745-758.

Garratt, J.A., Capri, E., Trevisan, M., Errera, G., and Wilkins, R.M., 2002, Parameterization, evaluation, and comparison of pesticide leaching models to data from a Bologna field site, Italy: Pesticide Management Science, v. 58, p. 3-20.

Healy, R.W., 1990, Simulation of solute transport in variably saturated porous media with supplemental information on modifications to the U.S. Geological Survey's Computer Program VS2D: U.S. Geological Survey Water-Resources Investigations Report 90-4025, 125 p.

Healy, R.W., and Ronan, A.D., 1996, Documentation of computer program VS2DH for simulation of energy transport in variably saturated porous media -- modification of the U.S. Geological Survey's computer program VS2DT: U.S. Geological Survey Water-Resources Investigations Report 96-4230, $36 \mathrm{p}$.

Hill, M.C., D'Agnese, F.A., and Faunt, C.C., 2000, Guidelines for model calibration and application to flow simulation in the Death Valley regional groundwater system, in Stauffer, F., Kinzelbach, W., Kovar, K., and Hoehn, E., eds., Calibration and Reliability in Groundwater Modelling: Coping with Uncertainty: Wallingford, International Association of Hydrological Sciences, p. 195-204.

Hsieh, P.A., Wingle, W., and Healy, R.W., 2000, VS2DI-A graphical software package for simulating fluid flow and solute or energy transport in variably saturated porous media: U.S. Geological Survey Water-Resources Investigations Report 99-4130, Lakewood, Colorado, 16 p.

Hutson, J.L., 2003, Leaching estimation and chemistry model: model description and user's guide: The Flinders University of South Australia, Adelaide, South Australia, 142 p.

Knisel, W.G., and Davis, F.M., 2000, GLEAMS: groundwater loading effects of agricultural management systems, version 3.0: Agricultural Research Service, U.S. Department of Agriculture, Publication No. SEWRL-WGK/FMD-050199, $191 \mathrm{p}$. 
Lappala, E.G., Healy, R.W., and Weeks, E.P., 1987, Documentation of computer program VS2D to solve the equations of fluid flow in variably saturated porous media: U.S. Geological Survey Water-Resources Investigations Report 83-4099, $184 \mathrm{p}$.

Ma L., and Selim, H.M., 1996, Atrazine retention and transport in soils: Environmental Contamination and Toxicology, v. 145 , p. $129-173$.

Schaap, M.G., Leij, F.J., and van Genuchten, M.T., 2001, ROSETTA: a computer program for estimating soil hydraulic parameters with hierarchical pedotransfer functions: Journal of Hydrology, v. 251, p. 163-176.

Šimůnek, J., Šejna, M., and van Gencuchten, M. Th., 1999, The HYDRUS-2D software package for simulating twodimensional movement of water, heat, and multiple solutes in variably saturated media. Version 2.0, IGWMC - TPS 53, International Ground Water Modeling Center, Colorado School of Mines, Golden, Colorado, 251pp., 1999.

van Genuchten, M. Th., 1980, A closed form equation for predicting the hydraulic conductivity of unsaturated soils: Soil Science Society of America Journal, v. 44, p. 892-898. 


\section{Appendix-Published Model Comparison Studies}

The references listed in this appendix are other model comparison studies published in journal articles, government reports, and conference proceedings.

Bergstrom, L.F., and Jarvis, N.J., 1994, Evaluation and comparison of pesticide leaching models for registration purposes: Journal of Environmental Science and Health, Part A, v. 29, p. 1061-1072.

Beulke S., Brown, C.D., Dubus, I.G., and Harris, G., 2001, Evaluation of uncalibrated preferential flow models against data for isoproturon movement to drains through a heavy clay soil: Pest Management Science, v. 57, p. 537-547.

Beulke S., Brown, C.D., Dubus, I.G., 1998, Evaluation of the use of preferential flow models to predict the movement of pesticides to water sources under UK conditions: Report to the U.K. Ministry of Agriculture, Food and Fisheries, MAFF project PL0516.

Beusen, A.H.W., Boekhold, A.E., Makaske, G.B. and van der Linden, A.M.A., 1997, Validation of the PESTLA model: Comparison of PRZM- 1, PELMO, LEACHP and PESTLA using the input data set for the Dutch standard scenario: RIVM report no. 715801006, Bilthoven, National Institute of Public Health and the Environment, The Netherlands.

Brown, C.D., and Hollis, J.M., 1995, Evaluation of the use of mathematical models to predict the fate of pesticides in the environment: SSLRC contract number 82//3725, SSLRC, Cranfield, UK.

Brown, C.D., Baer, U., Günther, P., Trevisan, M., and Walker, A., 1996, Ring test with the models LEACHP, PRZM-2 and VARLEACH: variability between model users in prediction of pesticide leaching using a standard data set: Pesticide Science, v. 47, p. 249-258.

Schierholz, I., Ritz, D., Kolle, O., Schäfer, D., Werner, M., 1996, The Weiherbach Data Set-an experimental data set for pesticide model testing on the field scale: Proceedings of the Xth Symposium on Pesticide Chemistry, Castelnuovo Fogliani, Italy, September 30 - October 2, 1996, p. 575-581.

Costa, J.L., Knighton, R.E., Prunty, L., 1994, Model comparison of unsaturated steady-state solute transport in a field plot: Soil Science Society of America Journal, v. 58, no. 5, p. 1277-1287.

Diekkruger, B., Söndergarth, D., Kersebaum, K.C., and McVoy, C.W., 1995, Validity of agroecosystem models: a comparison of results of different models applied to the same data set: Ecological Modeling, v. 81, p. 3-29.
Garratt, J.A., Capri, E., Trevisan, M., Errera, G., and Wilkins, R.M., Parameterisation, evaluation and comparison of pesticide leaching models to data from a Bologna field site, Italy: Pest Management Science, v. 58, p. 3-20.

Gottesburen, B., Mittlestaedt, W., and Führ, F., 1995, Comparison of different models to simulate the leaching behaviour of quinmerac predictively: Pesticide Movement to Water, BCPC Monograph No 62, ed. by Walker, A., Allen, R., Bailey, S.W., Blair, A.M., Brown, C.D., Gunther, P., Leake, C.R., and Nicholls, P.H., BCPC, Farnham Surrey, UK, pp 155-160.

Harter T., and Teutsch, G., 1990, Pesticide Transport Models: Comparison and Validation with Soil Column Leaching Experiments: in Weigman, D.L., 1990, Pesticides in the Next Decade: The Challenge Ahead, Proceedings of the Third National Research Conference on Pesticides, November 8-9, 1990, Virginia Water Resources Research Center, p. 725-750.

Larsson, A., Pers, K., Skagius, K., and Dverstorp, B., 1995, International INTRAVAL project to study validation of geospheric transport models for performance assessment of nuclear waste disposal, phase 2 summary report, Swedish Nuclear Power Inspectorate, Stockholm, 118 p.

Ogan, B.D., Wilson, G.V., Albright, W.H., Gee, G.W., Fayer, M.J., and Rock, S., Sensitivity analysis and validation of numerical models used in the design of alternative landfill covers: Annual Meeting of the Soil Science Society of America, Salt Lake City, Utah, October 31 - November 4, 1999.

Pennell, K.D., Hornsby, A.G., Jessup, R.E. and Rao, P.S.C., 1990, Evaluation of five simulation models for predicting aldicarb and bromide behaviour under field conditions: Water Resources Research, v. 26, p. 2679-2693.

Persicani, D., 1993, Atrazine leaching into ground watercomparison of five simulation models: Ecological Modeling, v. 70, p. 239-261.

Scanlon, B.R., Christman, M., Reedy, R.C., Porro, I., Šimůnek, J., and Flerchinger, G.N., 2002, Intercode comparisons for simulating water balance of surficial sediments in semiarid regions: Water Resources Research, doi:10.1029/2001WR001233.

Stothoff, S.A., 1997, Sensitivity of long-term bare soil infiltration simulations to hydraulic properties in an arid environment, Water Resources Research, v. 33, p. 547-558. 
Thorsen, M., Jørgensen, P.R., Felding, G., Jacobsen, O.H., Spliid, N.H., and Refsgaard, J.C., 1998, Evaluation of a stepwise procedure for comparative validation of pesticide leaching models: Journal of Environmental Quality, v. 27, p. 1183-1193.

Trevisan, M., Capri, E., and del Re, A.A.M., 1993, Pesticide soil transport models: model comparisons and field evaluation: Toxicological and Environmental Chemistry: v. 40, p. 71-81.

Trevisan, M., Capri, E., and del Re, A.A.M., 1994, Validation and comparison of pesticide soil transport models for field dissipation of metamitron: Environmental behaviour of pesticides and regulatory aspects, ed. by Copin, A., Hovins, G., Pussemier, L., and Salembier, J.F., European Study Service, Brussels, Belgium, p. 501-508.

Trevisan, M., Capri, E., del Re, A.A.M., Vischetti, C., Marini, M., Businelli, M., Donnarumma, L., Conte, A., and Imbroglini, G., 1995, Evaluation of pesticide leaching models using three Italian data-sets: Pesticide Movement to Water, BCPC Monograph No. 62, ed. by Walker, A., Allen, R., Bailey, S.W., Blair, A.M., Brown, C.D., Gunther, P., Leake, C.R., and Nicholls, P.H., BCPC, Farnham, Surrey, UK, p. 269-274.

Vanclooster, M., Boesten, J.J.T.I., and Trevisan, M., 2000, Pesticide leaching modelling validation: a European experience: Agricultural Water Management, v. 44, p. 1-409.

Vink, J.P.M., Gottesbüren, B., Diekkrüger, B., and van der Zee, S.E.A.T.M., 1997, Simulation and model comparison of unsaturated movement of pesticides from a large clay lysimeter: Ecological Modeling, v. 105, p. 113-127.

Walker, A., Welch, S.J., Melacini, A., and Moon, Y.H., 1996, Evaluation of three pesticide leaching models with experimental data for alachlor, atrazine and metribuzin: Weed Research, v. 36, p. 37-47 